\title{
Particle release from drug eluting balloons and stents - simulated use testing
}

L. Thieme, M. Kraft, Fachgebiet Medizintechnik, TU Berlin, Berlin, Germany, Lucas.Thieme@TU-Berlin.de

\section{Introduction}

Particles released in the coronary arteries or a carotid artery during interventions such as percutaneous transluminal coronary angioplasty (ptca) can cause complications such as occlusions of small vessels or capillaries, leading to micro embolisations and increasing the risk of the no-reflow phenomenon. The aim is to develop and implement simulated use testing methods and to analyse mechanisms and consequences of particle release of drug eluting balloons and stents.

\section{Methods}

A circulation model has been developed to simulate flow, pressure and vessel wall movements of the human coronary arteries. Particles released during simulated ptca-interventions are captured and analysed. Using a liquid particle counter, filters, scanning electron microscopy and light microscopy, quantity, size form and likely origin of the particles are determined.

\section{Results}

The developed test bench supports the design process of products used for catheter based interventions, concerning particle release and coating durability. Furthermore the influence of physiological parameters like blood flow conditions, vessel wall structure, and vessel geometry on the particle release from stents and ptca-Balloons can be investigated.

\section{Conclusion}

To prove safety, investigation of products used for catheter based interventions concerning particle release, is necessary. The presented test bench allows to perform the necessary testing, further it is applicable to investigate the behavior of the coating concerning different release media, flow conditions and artificial anatomies of the heart. 